\title{
THE STRUCTURAL FUNCTION OF THE DUTCH BUTTRESSING OF THE EAST CURTAIN WALL OF ELMINA CASTLE, ELMINA, GHANA
}

\author{
JIACHENG SUN ${ }^{1}$, SELMAN TEZCAN ${ }^{1}$ AND RENATO PERUCCHIO ${ }^{2 *}$ \\ ${ }^{1}$ Department of Mechanical Engineering \\ University of Rochester, Rochester, NY 14627, USA \\ e-mail: \{jsun29, stezcan\}@ur.rochester.edu \\ *Department of Mechanical Engineering, and \\ Program of Archaeology, Technology and Historical Structures \\ University of Rochester, Rochester, NY 14627, USA \\ e-mail: renato.perucchio@rochester.edu
}

Keywords: Elmina Castle, Masonry Wall, Lateral Capacity, Non-Linear FE Explicit Analysis, Concrete Damaged Plasticity, Abaqus/CAE.

\begin{abstract}
Elmina Castle is the first of a series of European trading bases along Africa's west coast, and it is the oldest and best preserved early European building in Sub-Saharan Africa. The structure shows a combination of mud-mortared and lime-mortared sandstone masonry macro elements and has undergone reconstructions and modification throughout time under Portuguese and Dutch occupation. This study focuses on the structural analysis of Elmina Castle's east curtain wall, which features two massive masonry buttresses built only along selected portions of the wall. The hypothesis that these buttresses were built in correspondence of deep voids in the foundation bedrock platform is numerically evaluated using pushover analysis. The lateral capacity is determined based on energy considerations using nonlinear FE models in Abaqus/CAE Explicit and concrete damaged plasticity. Results indicate that, at a later Dutch stage of structural modification, loose soil filling might have caused rotational instability of the curtain wall, requiring the addition of the buttresses.
\end{abstract}

\section{INTRODUCTION}

As the oldest and best preserved early European building in Sub-Saharan Africa, Elmina Castle is the first of a series of trading bases along Africa's West Coast. Erected in 1482 by the Portuguese Crown to protect its control of the gold trade, after the 1637 Dutch conquest the castle became a major hub of the Atlantic Slave Trade involving Europe, Africa, and the Americas. Acquired by the British in 1872, the castle came under control of Ghana with the country independence in 1957 and is currently part of a UNESCO World Heritage Site in Ghana.

The Elmina Castle has been the object of a multidisciplinary (engineering and historical archeology) field school conducted at Elmina, Ghana, by the Archaeology, Technology, and Historical Structures program of the University of Rochester in summer 2017 and 2018. At the present time, the building consists of an inner keep of three-story buildings and a large courtyard surrounded by curtain walls, with bastions at the southeast, southwest, and northeast corners (Figure 1). The structure shows a combination of mud-mortared and lime-mortared sandstone 
masonry macro elements, incorporating original 1482 Portuguese elements (towers, walls) with successive Portuguese, Dutch, and British reconstructions and modifications. European built fired-clay bricks were first used sparingly by the Portuguese for windows and doors openings, and then in very large number for extensive vault construction by the Dutch.

The present paper focusses on the structural analysis of the east curtain wall which features two massive masonry buttresses which reach up to the parapet but were built only along selected portions of the wall (Figure 2). Historical documents clearly show that these buttresses are a Dutch addition, since they do not appear in the only drawing showing the castle still in Portuguese hands in 1637 (Figure 3). However, they are present in detailed - and particularly accurate - Dutch maps of the second half of the 1700's [1]. Similar to the western curtain wall, the original eastern curtain wall appears to be built with foundation resting on levelled limestone bedrock, as reported by the Portuguese chronicles describing the 1482 construction process [2]. The laser-scan and photogrammetric survey conducted during the field school and information extracted from the historical record allow us to construct a reasonably accurate building sequence beginning from late Portuguese period (before 1637) to the mid 1700's.
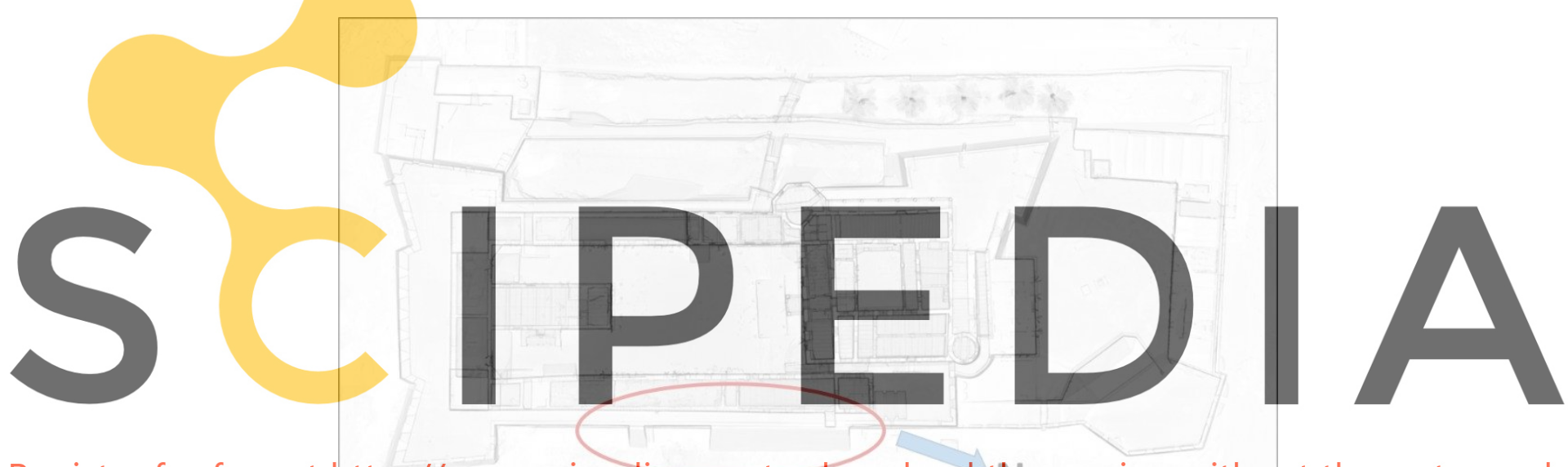

Register for free at https//www.scipedia.com to download the version without the watermark

Figure 1: Elmina Castle floor plan with Dutch buttress highlighted, based on 2017-2018 FARO scans taken by Michael Jarvis - U. Rochester/ U. Ghana, Field school.

The late Portuguese east wall was extended in elevation and considerably thickened with mud-mortared masonry covered by lime plaster, and a two-story building was added along its entire length, with the inner side of the curtain wall becoming part of the new building. The first (ground) story of the building is vaulted with a $4 \mathrm{~m}$-span barrel vault approximately $16 \mathrm{~cm}$ thick (the length of an average Dutch brick). This thin vault - excellently executed with bricks interlocking in two directions - carries a considerable dead load of loose material $1 \mathrm{~m}$ deep at the crown and is in undamaged structural conditions. To explain the presence of the irregular buttressing architecture noted above, we make the following hypothesis (Figure 2b). The section of the original Portuguese wall later covered by the buttress is likely not built on the bedrock but on compacted loose soil and debris used to fill a void where the bedrock dips below the level of the courtyard. Using compacted loose soil to fill such voids is largely attested in other European forts along the coast of Ghana. The wall carried by this weaker foundation could 
have been damaged by the 1615 earthquake in Elmina or by the Dutch assault on the castle, or both. The dead loads introduced with the extension and thickening of the wall and the construction of the vaulted building could possibly have caused concerns in the Dutch builders, who, noticing signs of rotational instability, reinforced the wall with a buttressing system limited only to the affected areas. We test the structural conditions on which the hypothesis is based through a sequence of 2- and 3D nonlinear FE models, by first testing how the presence of a pocket of loose soil affects the structural response of the Portuguese wall under lateral accelerations, then testing the structural effect of the Dutch modifications to the wall, and finally introducing the effect of the vaulted building. In modeling the curtain wall, we test separately the case of a solid masonry wall or, as it is more likely, of a wall with an internal mass of loose material bounded by external and internal masonry curtain. The masonry physical characterization is based on published material and the nonlinear mechanical behavior is modeled through the concrete damaged plasticity formulation available in Abaqus/CAE

\section{Explicit.}

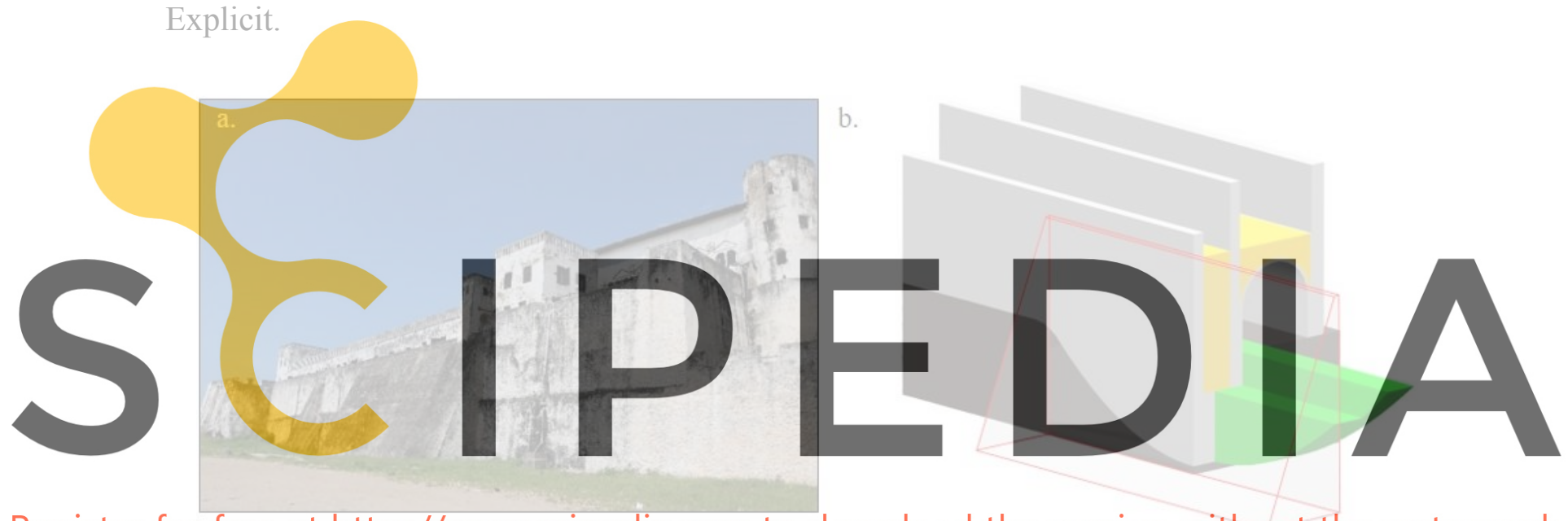

Register for free at https//www.scipedia.com to download the version without the watermark

Figure 2: (a) East curtain wall and buttressing wall in current condition; (b) Hypothesized wall and foundation composition behind buttresses.

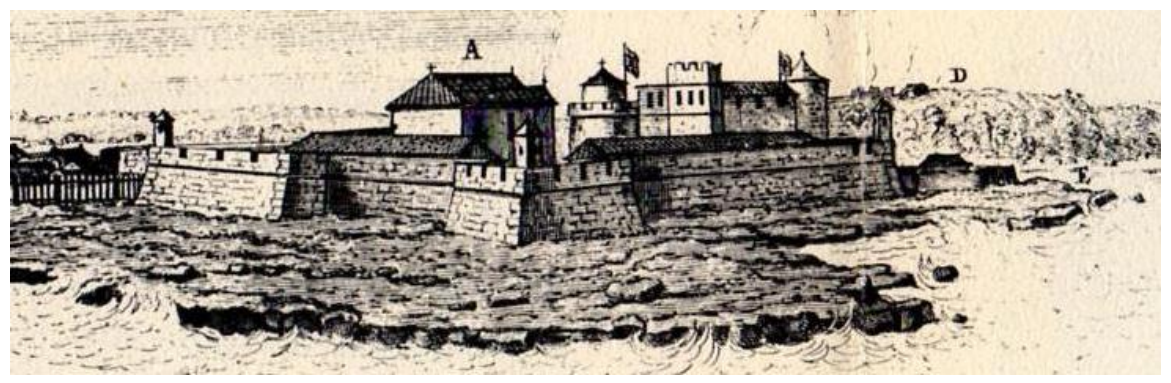

Figure 3: Elmina Castle in 1637, Frans Post, 1637 [3].

\section{METHODOLOGY}

Pushover analysis is a well-established approach for assessing the overall behavior of a structure due to seismic activity that uses an incremental-iterative solution based on static equilibrium to determine the response of the structure under monotonically growing lateral load 
patterns [4] [5]. These can be implemented by lateral displacements or forces applied to one side of the structure or by subjecting the entire structure to a uniformly applied horizontal acceleration. In this study, after gravitational loading, a uniform monotonically increasing horizontal acceleration is applied to the entire model using the explicit FE formulation available in Abaqus. The desired quasi-static condition is enforced by adopting long time intervals for the application of both gravitation and lateral accelerations: for example, five seconds for gravitation to increase linearly from 0 to $1 \mathrm{~g}$ followed by ten seconds for lateral acceleration to go from 0 to $0.8 \mathrm{~g}$.

The time-evolution of strain (SE), kinetic (KE), and dissipative energy (PD - due to plastic deformations simulating internal fractures) is used to identify the development of local damage conditions up to structural collapse (Figure 4a). As long as structural integrity is maintained under increasing lateral acceleration, KE remains negligible during the evolution of quasi-static structural response. Structural failure is associated with the sudden transition from quasi-static to a fully dynamic state and is detected by the accompanying asymptotic growth of KE. In the example shown, PD follows an identical asymptotic growth pattern, while SE immediately decreases after having reached a peak at failure. Notice also that the viscous dissipative energy (VD) produced by the fictitious viscosity parameter used in Abaqus/CAE Explicit to dampen possible oscillatory behavior remains negligible during static conditions and then goes asymptotic at failure. Figure $4 \mathrm{~b}$ shows the concomitant time-evolution of the horizontal and vertical reactions normalized by the weight of the wall and expressed as fractions of g. As a result of the inertial forces caused by the applied lateral acceleration, an equilibrating horizontal reaction force (basal s only gravitational load is a gradual application of lateral acceleration causes time while the vertical reactions hold constant. indicating that the struct the mass of the wall has nearly completely separated from its base. As expected, failure occurs

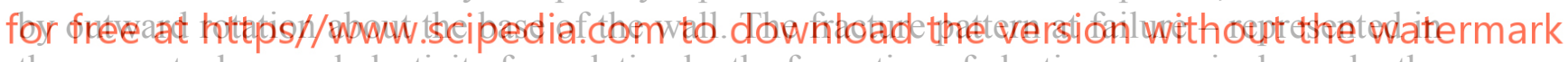
the concrete damaged plasticity formulation by the formation of plastic zones - is shown by the black band on the inner side at the base of the wall in the insets of Figure $4 \mathrm{a}$.

The examination of the energy and reaction plots in Figure 4 suggests complementary ways to associate a specific time interval to failure. KE begins to develop at $7.3 \mathrm{~s}$ and becomes asymptotic at $7.9 \mathrm{~s}$, reaching the $10 \%$ value of the total internal energy (i.e. SE $+\mathrm{PD}+\mathrm{KE}$ ) at $7.7 \mathrm{~s}$. PD, which can be taken to represent the work necessary to propagate the fractures at the base of the wall, begins to appear at $6.6 \mathrm{~s}$ and crosses the SE at $7.85 \mathrm{~s}$. Thus, purely on energy considerations, total failure can be reasonably defined to happen between $t=7.7 \mathrm{~s}$ (when the loading process cannot anymore be regarded as static) and $t=7.85 \mathrm{~s}$ (when the PD equals the $\mathrm{SE})$. Hereafter we will use the $10 \%$ kinetic energy criterion to determine failure.

The explicit (dynamic) nonlinear FE formulation is preferred over the implicit one because of its capability to sustain large deformations and attendant local material failures, and to capture unequivocally the collapse condition due to lateral accelerations [6]. In fact, in most of the cases of the present study, it may be not possible to detect the actual failure condition using an implicit nonlinear FE formulation because the analysis terminates due to numerical error (e.g., the stiffness matrix becomes singular) before the actual structural failure occurs. On the negative side, dynamic explicit models are computationally costly. In order to ensure 
algorithmic convergences, Abaqus Explicit requires the time increments of the order of $10^{-6}$ second for both gravitation and lateral acceleration [7].
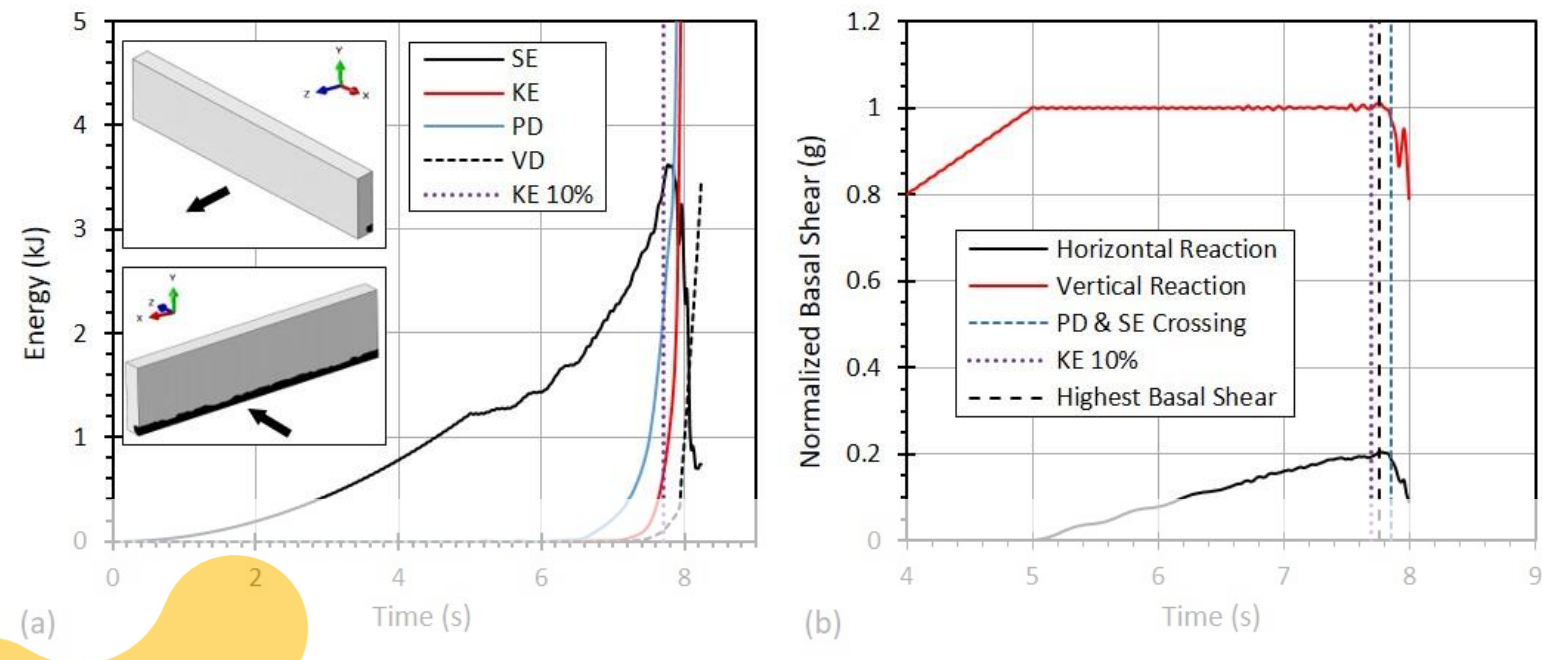

Figure 4: (a) Energy curves versus analysis time; (b) Normalized reaction force versus analysis time.

The geometric mode

Thus, the 3D "P" model curtain wall's height de

the curtain wall and the

cases, the wall length, th
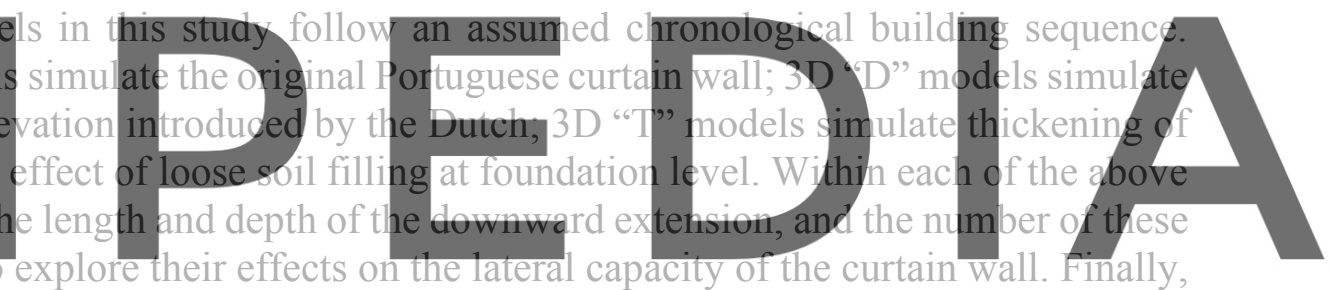

we use 2D "V" models to simulate the effect of construction of a vaulted structure against the

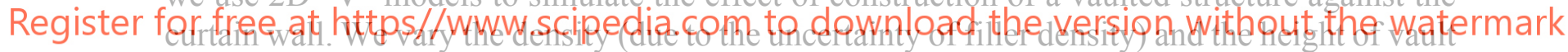

filling (due to possible variation of filler thickness from historical map from 1774 [8]) to explore

their effects on structural capacity of the curtain wall. The "V" modeis are then expiored with the effect of adding the external buttressing walls. Figure 5a shows a basic "P" model. Due to symmetry, only half the length is represented. The wall thickness is taken as $1.3 \mathrm{~m}$ based on the measured thickness of the exterior wall at the current "door of no return" where the original Portuguese structure is still visible. The height of the original Portuguese curtain wall is taken as $2 \mathrm{~m}$ based on Frans Post's 1637 drawing shown in Figure 3, in which the height ratio between curtain wall and bedrock platform is $2: 5$. Figure 5 b shows a basic " $D$ " model with wall thickness unchanged from "P" models and the height elevated to $5 \mathrm{~m}$, which is the current measured wall height. As shown in Figure 1, the two buttresses have different lengths: the southern is $4 \mathrm{~m}$ long while the northern is $20 \mathrm{~m}$ long. To explore the possible downward configurations of the curtain wall in correspondence of these two buttresses, we consider the length of the downward extension to be either $1 \mathrm{~m}$ or $10 \mathrm{~m}$, and as for the long buttress, the possible presence of either one or two extensions. As for the depths of the extensions, we assume either $2.5 \mathrm{~m}$ or $5 \mathrm{~m}$. Notice that the P/D0 models represent the uniform wall without downward extension. The 
various subcases are summarized in Table 1 . Notice also that in this table " $\mathrm{A}$ " indicates the curtain wall with two downward extension dips for the specific subcase.

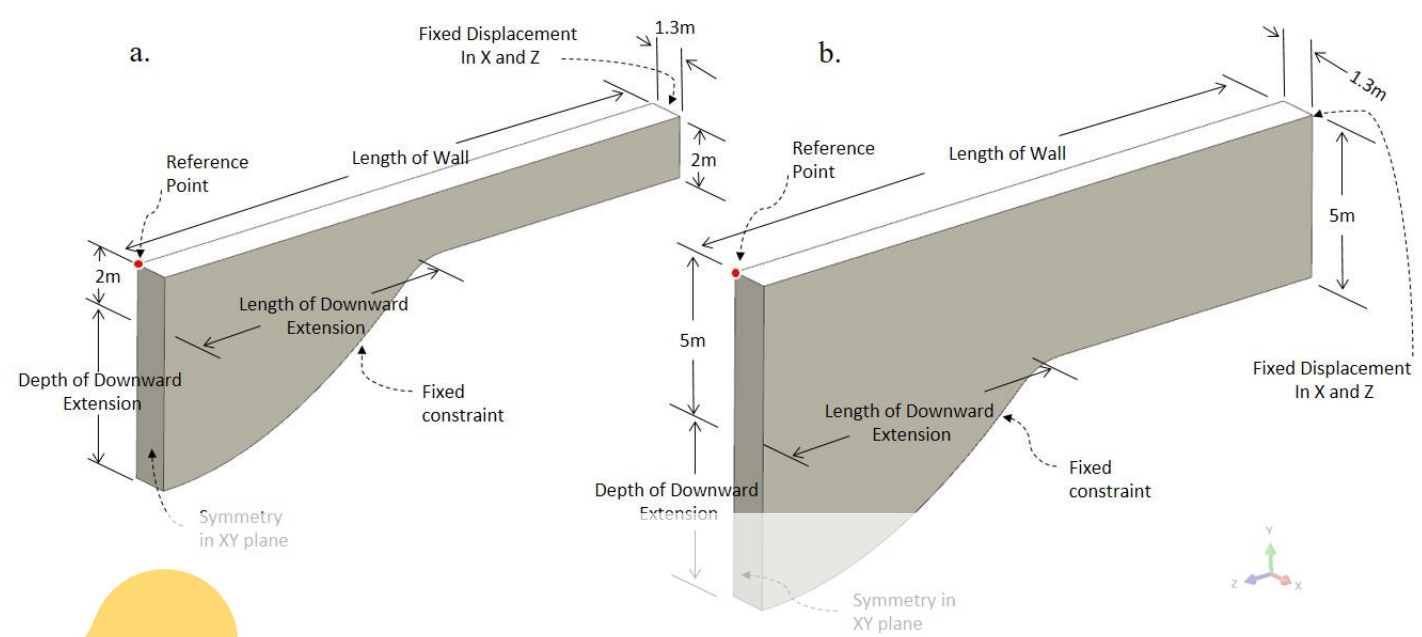

Figure 5: (a) Dimensions of basic "P" model; (b) Dimensions of basic "D" model.

For the "T" models, the thickness and the height are taken as $3 \mathrm{~m}$ and $5 \mathrm{~m}$, respectively, based on the current wall thickness and height. In correspondences of the voids of the bedrock, the thickened wall is 6b. As stated above, sim coast of Ghana. The bedr eastward inclination. As created to represent the and number (Table 1 ).
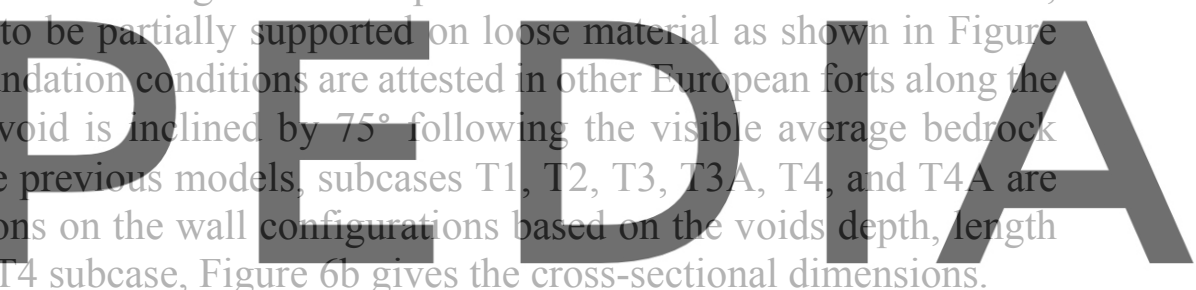

The "V" models represent east curtain wall with the construction of vaulted structure. Figure

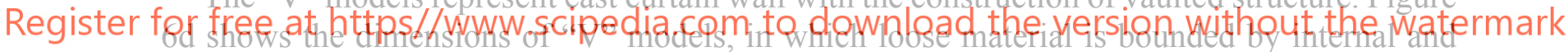
external masonry curtain walls. Only one depth $(5 \mathrm{~m})$ of downward wall and soil extension is explored in the "V" case, and subcases (VA and VB) are created to explore the effect of the construction of buttressing on the curtain wall with vaults in place.

Table 1: Dimensions of subcases with reference to Figure 5.

\begin{tabular}{|c|c|c|c|c|}
\hline Configuration & Length of wall $(\mathrm{m})$ & $\begin{array}{c}\text { Depth of downward extension } \\
(\mathrm{m})\end{array}$ & $\begin{array}{c}\text { Length of Downward } \\
\text { Extension }(\mathrm{m})\end{array}$ & Number of Dips \\
\hline P/D0 & 10 & 0 & 0 & 0 \\
\hline P/D/T1 & 10 & 2.5 & 1 & 1 \\
\hline P/D/T2 & 10 & 5 & 1 & 1 \\
\hline P/D/T3 & 20 & 2.5 & 10 & 1 \\
\hline P/D/T3A & 20 & 2.5 & 10 & 2 \\
\hline P/D/T4 & 20 & 5 & 10 & 1 \\
\hline P/D/T4A & 20 & 5 & 10 & 2 \\
\hline
\end{tabular}

Quadratic tetrahedral elements and quadratic triangular plane strain elements are used for 3D and 2D models, respectively. Figure $6 \mathrm{a}$ and $6 \mathrm{c}$ show the mesh and material distribution for T4 and VA. Grey indicates mud mortar (adobe in Table 2), green indicates stone masonry 
(masonry in Table 2), yellow indicates loose material (lateritic soil in Table 2), and purple indicates sandstone. For all models, the base of the curtain wall is tie-constrained to the sandstone surfaces. Surface to surface contact is defined for all other surface contact interactions.

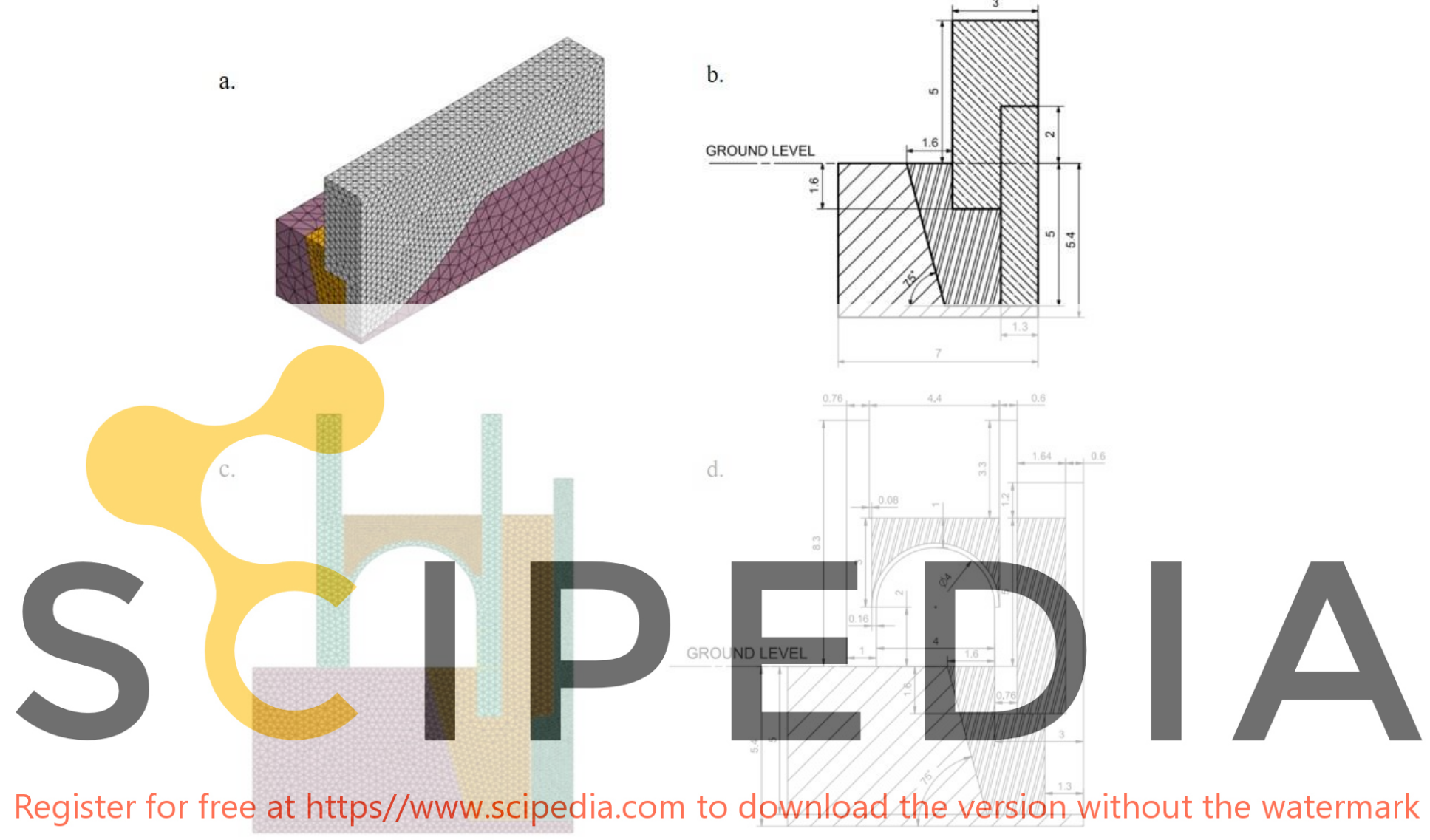

Figure 6: (a) T4 model shown with color-coded material distribution; (b) Dimensions of T4 model cross-section at deepest downward wall extension; (c) VA model shown with color-coded material distribution; (d) Dimension of "VA" model. (All units are shown in meters).

\section{MATERIALS}

The concrete damaged plasticity model in Abaqus/CAE is primarily intended to provide a general capability for the analysis of concrete structures under dynamic/cyclic loading. The model is also suitable for the analysis of quasi-brittle material such as mortar [9]. It is a plasticity-based model that assumes the two main failure mechanisms for the concrete material are tensile cracking and compressive crushing. The material's brittle behavior can be characterized by a stress-displacement response under tension and by a stress-strain response under compression [10]. We use concrete damaged plasticity to model post critical behavior of mud mortar (adobe in Table 2) and stone masonry (rough-hewed stone in Table 2). General concrete damaged plasticity parameters shown in Table 2 are taken from Tarque [11], and elastic material properties of stone masonry are taken as the average of the range of roughhewed stone [12]. The post critical softening compressive behavior is represented parabolically, 
and the post critical softening tensile behavior is represented by exponential decay. The tabulated values of mud mortar's post critical behaviors are taken from previous research [13]. The tabulated values for stone masonry's post critical behaviors are hypothesized to be between that of mud mortar and Roman pozzolanic concrete [14]. Therefore, both post critical behaviors are scaled down from those of pozzolanic concrete based on stone masonry's compressive and tensile strength [12]. For two subcases in "V" models, Mohr-Coulomb model is used to represent loose material filling. Mohr-Coulomb criterion assumes that yield occurs when the shear stress on any point in a material reaches a value that depends linearly on the normal stress in the same plane [15]. The parameters needed to construct Mohr-Coulomb model are obtained based on previous research and are documented in Table 2.

Table 2: Material properties used in this study.

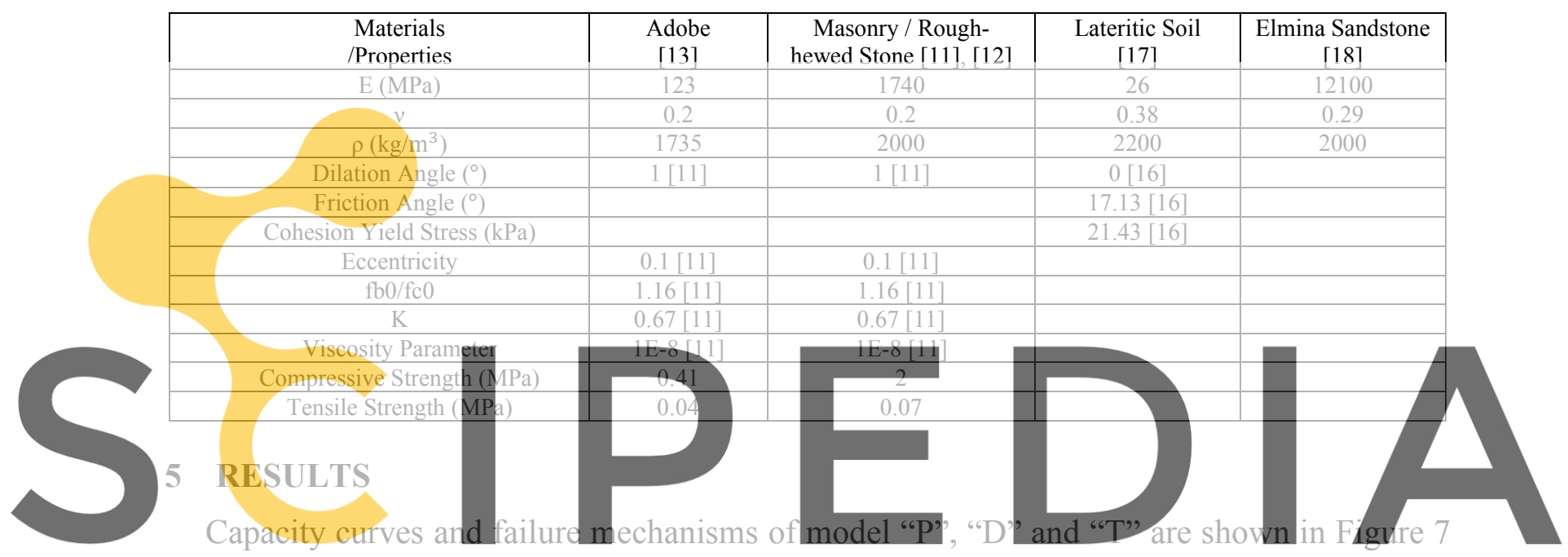

to Figure 9. Displacements are measured at the reference point (Figure 5), a point with the Register forgfiedial antepspywwww.scipedia.com to download the version without the watermark
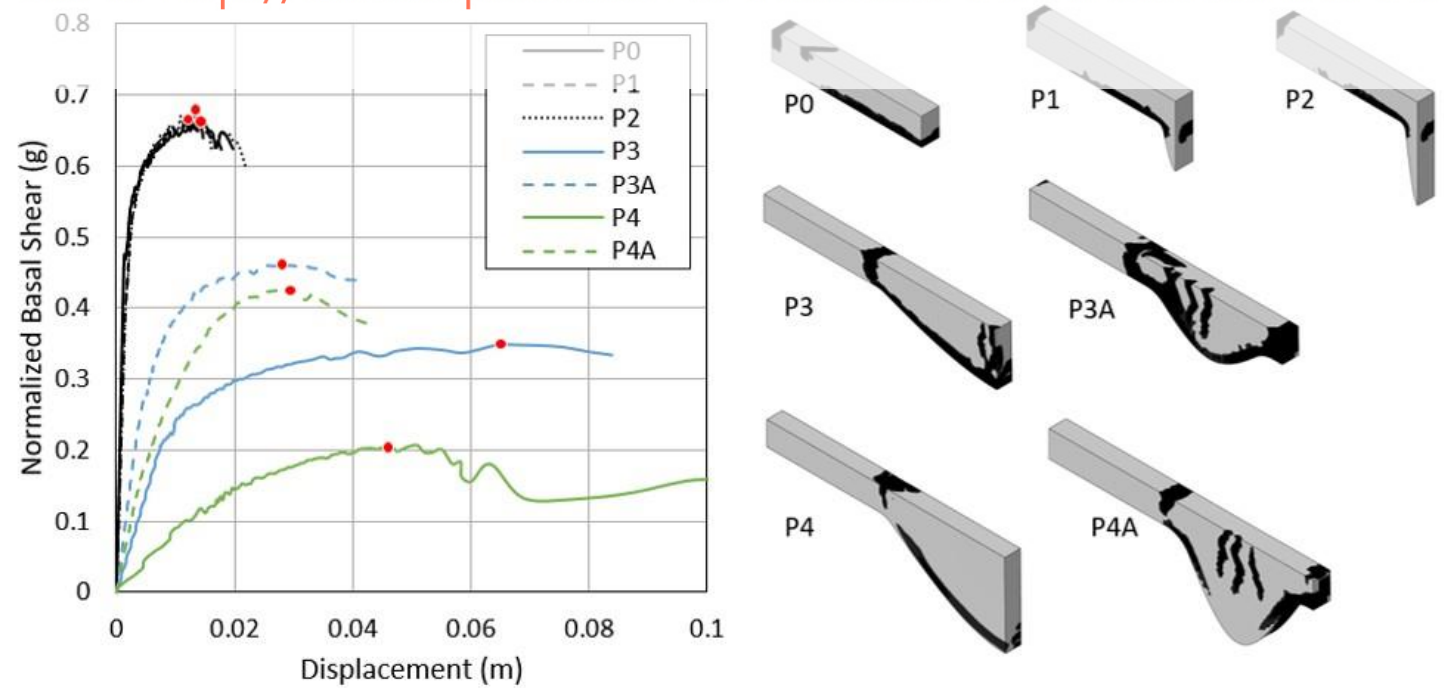

Figure 7: Capacity curves and failure mechanisms of "P" subcases. 
Capacity curves and failure mechanisms of P0, P1 and P2 show that structural capacity and stiffness are not sensitive to downward wall extension when its length is small compared to wall length. They also show that structural capacity and stiffness are sensitive to the length and depth of downward wall extension. The same observations can be made for both " $D$ " and "T" models. The worst structural condition in "P" models, P4, gives a structural capacity of $0.21 \mathrm{~g}$ in resisting lateral acceleration. However, due to the increase in wall height, structural capacity and stiffness in "D" models have both decreased. The worst structural condition in "D" models, $\mathrm{D} 4$, gives a structural capacity of $0.14 \mathrm{~g}$ in resisting lateral acceleration. The worst structural condition in " $\mathrm{T}$ " models, T4, gives an increased structural capacity of $0.23 \mathrm{~g}$ in resisting lateral acceleration due to thickening of the curtain wall.
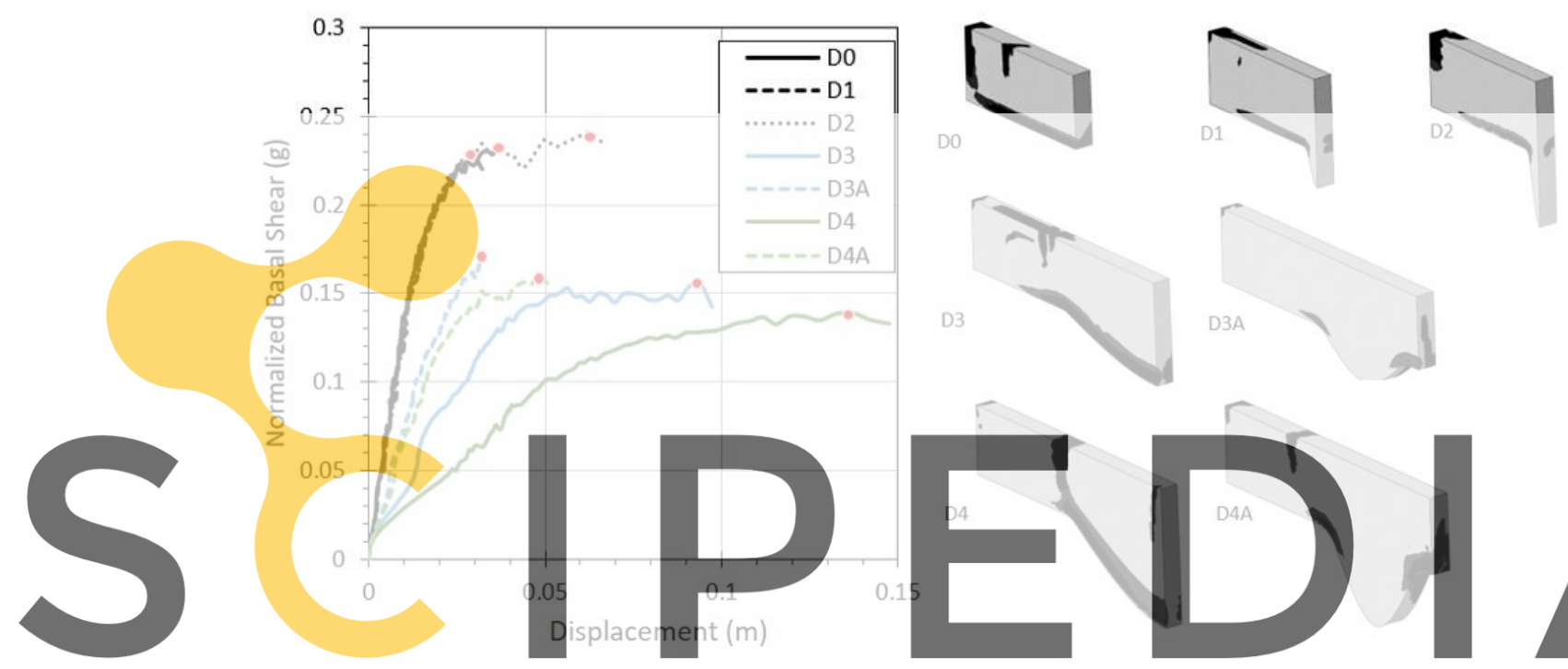

Figure 8: Capacity curves and failure mechanisms of "D" subcases.

Register for free at https//Www.scipedia.com to download the version without the watermark

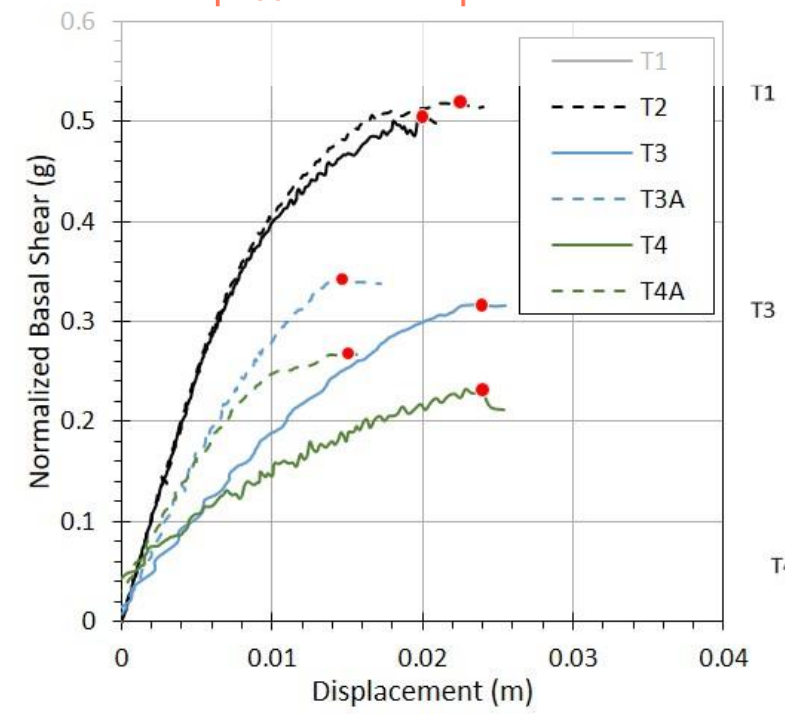

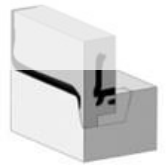
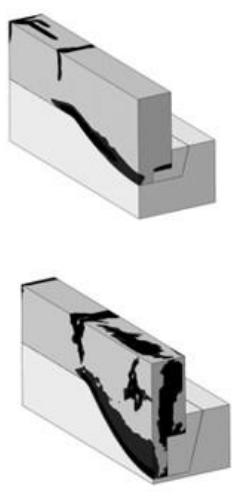

12

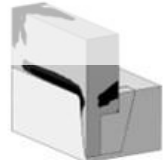

T3A

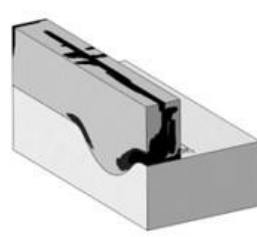

T4A

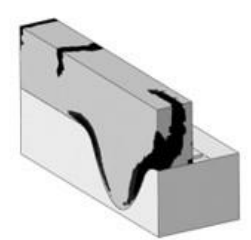

Figure 9: Capacity curves and failure mechanisms of " $T$ " subcases. 
For model VA, the density is varied $(2200 \mathrm{~kg} / \mathrm{m} 3,1600 \mathrm{~kg} / \mathrm{m} 3$, and $1200 \mathrm{~kg} / \mathrm{m} 3)$ for the loose material filling above the vault with its other material properties unchanged, resulting in models VA1, VA2, and VA3 respectively. The three models are repeated with half the vault filler thickness $(0.42 \mathrm{~m})$, resulting in models VA4, VA5, and VA6 respectively. For model VB, lateral acceleration is applied toward (VB1) and away (VB2) from the external curtain wall. For VA and VB1 models, failure takes place by outward rotation of external curtain wall. For model VB2, failure takes place by outward rotation of inner wall. Therefore, the structural failures of model VA and VB1 are determined from energy curves of the external curtain wall, and the structural failure of VB2 are determined from energy curves of inner wall. The structural capacities are hence shown in Table 3, and failure mechanisms of model VA1, VB1, and VB2 are shown in Figure 10.

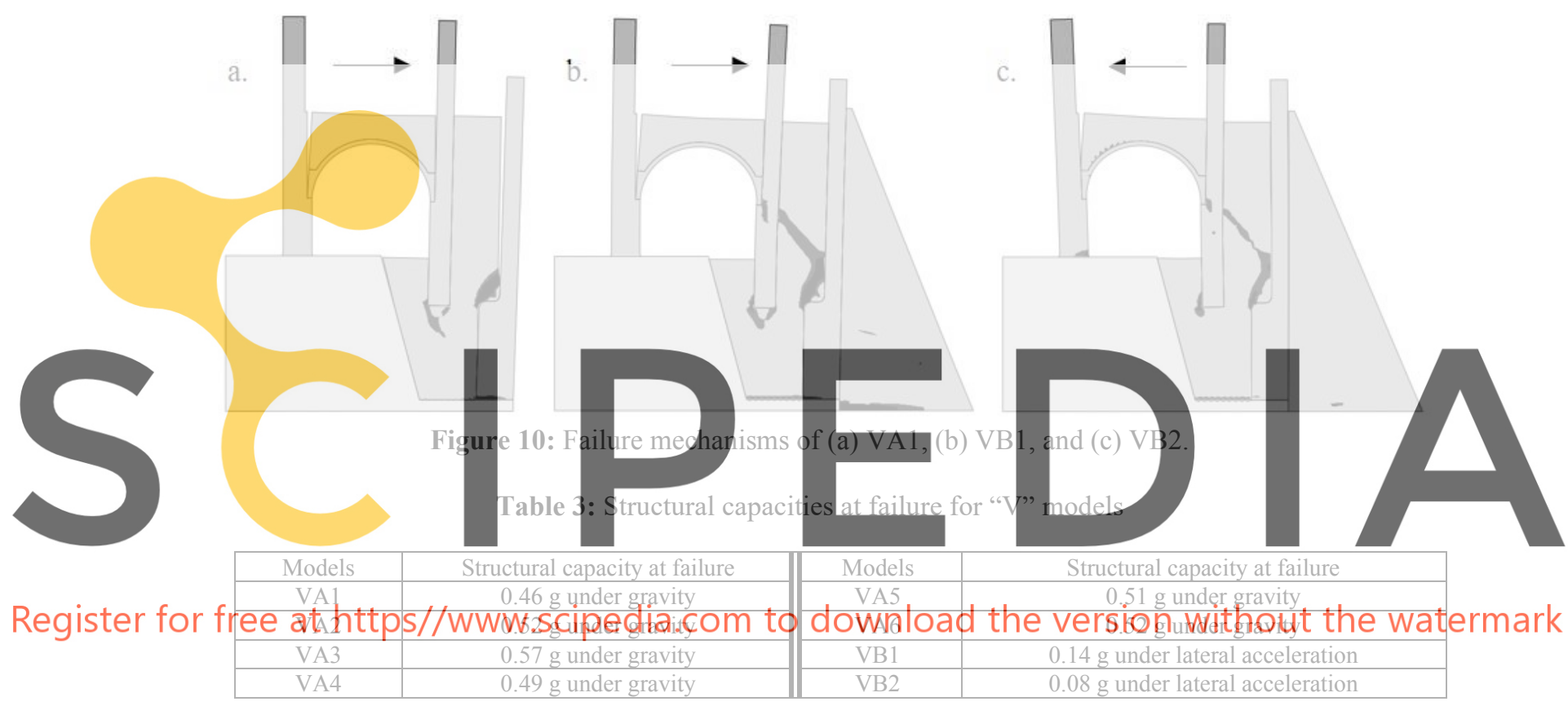

The structural capacities at failure shown in Table 3 for VA1 - VA3 and VA4 - VA6 indicate that the structural capacity of the external curtain wall is not sensitive to the density and thickness of loose material filling above the vault. However, as expected, it is altered by the addition of the supporting buttress.

\section{DISCUSSION}

The presence of the bedrock voids and the attendant downward extensions of the curtain wall induces localized failures that lower the lateral capacity of the external curtain wall to $0.21 \mathrm{~g}$, $0.14 \mathrm{~g}$, and $0.23 \mathrm{~g}$ for the "P", "D", and "T" configurations respectively. The peak ground acceleration (PGA) of the coastal region of Ghana ranges from $0.026 \mathrm{~g}$ to $0.2 \mathrm{~g}$ [19]. Considering the proximity to Cape Coast, we take the PGA of the Elmina area to be $0.05 \mathrm{~g}$. Given this value of PGA, all the possible Portuguese and early Dutch configurations considered here are likely to have survived seismic action. This picture may have changed dramatically when the Dutch built the vaulted system along the entire curtain wall. As shown by model VA, 
without the counterbalancing presence of the external buttress, the vaulted system would fail during construction in correspondence of the bedrock void by the combination of the pressure exerted on the loose soil and the effect of the lateral thrust generated by the vault itself. The addition of the buttress (model VB) stabilizes the external curtain wall under static conditions. However, the results of VB2 show that a minimal amount of lateral acceleration directed away from the curtain wall would bring structural failure to the inner wall, indicating that the structure is still prone to collapse under a very modest seismic action.

In conclusion, this initial study suggests that while a Portuguese $2 \mathrm{~m}$ high curtain wall would have survived local seismic action, the height elevation to $5 \mathrm{~m}$ due to the Dutch would have considerably weakened the structure. Noticing possible signs of rotational instability, the Dutch builders would have likely thickened the curtain wall to the current dimensions. Thus, under the conservative hypothesis that the wall was initially made entirely of mud-mortared masonry, the analysis shows that the thickened structure would again be able to sustain the same level of seismic activity as the original Portuguese curtain wall. At a later stage, before the introduction of the vaulted system, following a common procedure, the Dutch reconstructed the curtain wall as an external and internal curtain made of lime-mortared rough stones bounding a loose material filling. The construction of the vaults is likely to have caused concerns about failure conditions in correspondence of the bedrock voids, and thus would have required the addition of the present buttressing system. Finally, we note that the 2D plane strain models adopted to test the "V" configurations overestimate the effect of the soil filling. Under actual 3D conditions, portion of the vaulted structure is supported by bedrock, which would help stabilize the portion built on soil, as shown in the failure mechanisms of the " $T$ " models. This issue will be addressed in future work.

Acknowledgements. We thank Michael Jarvis and Christopher Muir for their contributions to the surveying of Elmina Castle. Louisa Anderson helped us in establishing the early Portuguese architecture. Global engagement provided support through Global Partnership Fund travel support to Jiacheng Sun.

\section{REFERENCES}

[1] Lawrence, A.W. Trade castles and forts of West Africa. Jonathan Cape, (1963).

[2] Hair, P. E. H. The Founding of the Castelo De São Jorge Da Mina: An Analysis of the Sources. Madison: African Studies Program, University of Wisconsin-Madison, (1994).

[3] Post, F. Sao Jorge da Mina. Dutch National Archive (1637).

[4] Pinho, R. Using pushover analysis for assessment of building and bridges. Advanced earthquake engineering analysis, International Center of Mechanical Sciences 494 (2007), pp. 91-120.

[5] Chopra, A. K. Dynamics of Structure: Theory and Applications to Earthquake Engineering, Pearson/Prentice Hall, Upper Saddle River, New Jersey (2007).

[6] Tezcan, S., Tambe, N., Muir, C., Perucchio, R. Nonlinear FE analysis of the response to lateral accelerations of the triumphal arch of the church of Andahuaylillas, In: R. Aguilar et al. (Eds.): Structural Analysis of Historical Constructions, RILEM Bookseries 18 (2019), pp. 1301-1309. 
[7] Abaqus Analysis User's Manual Simulia v.6.14.6.3.3 Explicit dynamic analysis. Dassault System Corporation, Providence, RI (2018).

[8] The Hague, Collection Foreign Maps Leupe, number access 4. Vel, inventory number 779A, Dutch National Archive, (1774).

[9] Abaqus documentations, Concrete damaged plasticity, (2017). https://abaqus-docs.mit.edu/2017/English/SIMACAEMATRefMap/simamat-cconcretedamaged.htm

[10] Abaqus Theory Manual, 4.5.2 Damaged plasticity model for concrete and other quasibrittle materials, (2009).

https://classes.engineering.wustl.edu/2009/spring/mase5513/abaqus/docs/v6.6 books/stm/default.htm?startat=ch04s05ath120.html"

[11] Tarque, N. Numerical modelling of the seismic behavior of adobe building. PhD dissertation, Universitá degli Studi di Pavia, Italy, (2011).

[12] Angelillo, M., Lourenco, P.B., Milani, G. Masonry behavior and modelling. Mechanics of Masonry Structures, CISM international center for mechanical sciences, Vol 551, Springer, Vienna, (2014), pp. 1-26.

[13] Aguilar, R., Zavala, G, Pando, M.A., Briceno, C., Zavala, G., Castaneda, B., Perucchio, R., Uceda, S. Structural and geotechnical engineering assessment of Huaca de la Luna - A massive earthen Moche culture pyramid in Norther Peru. Journal of Cultural Heritage 34, Elsevier Masson SAS, (2018), pp.83-94.

[14] Brune, Philip F. The Mechanics of Imperial Roman Concrete and the Structural Design of Vaulted Monuments. Thesis: Department of Mechanical Engineering, Arts, Science and Engineering, University of Rochester, (2010).

[15] Abaqus documentations Mohr-Coulomb plasticity, (2017). https://abaqus-docs.mit.edu/2017/English/SIMACAEMATRefMap/simamat-cmohrcoulomb.htm

[16] Chen L.J., Dai Z.H., Liu Z.W. Three-dimensional nonlinear finite element analysis of soft soil excavation engineering considering K0 consolidation. Rock Soil Mech. 32(12) (in Chinese), (2011), pp. 3796-3804.

[17] Fall, M., Sarr, D., Ba, M. Evolution of lateritic soils geotechnical parameters during a multicyclic OPM compaction and correlation with road traffic. Geomaterials 1, (2011), pp. 2969.

[18]Zhu, T. Some Useful Numbers on the Engineering Properties of Materials. http://www.jsg.utexas.edu/tyzhu/files/Some-useful-numbers.pdf. University of Texas, (2014).

[19] Ahulu, S. T., Danuor, S. K., and Asiedu, D. K. Probabilistic seismic hazard assessment of southern part of Ghana. Journal of Seismology, 22(3), (2017), pp. 539-557. 